\title{
Spontaneous Expulsion per Rectum of a Colorectal Polyp: A Rare and Unusual Case
}

\author{
Jamil Shah ${ }^{\mathrm{a}, \mathrm{c}}$, Abul Shahidullah ${ }^{\mathrm{b}}$
}

\begin{abstract}
Colorectal polyps are growths that form on the epithelium of the colon and rectum. While their prevalence varies considerably from region to region, they are common in adults. In fact, among asymptomatic, average-risk individuals at 50 years of age, the prevalence of colorectal polyps averages roughly $10 \%$ in sigmoidoscopy studies and more than $25 \%$ in colonoscopy studies. Approximately two-thirds of all colorectal polyps are adenomatous precancerous lesions that have the potential to become malignant. Usually, they are discovered and resected during colonoscopy. The spontaneous expulsion per rectum of a colorectal polyp is exceedingly rare. Here, we report a rare and unusual case that we believe is the first of spontaneous expulsion of an adenomatous polyp during defecation. These patients should undergo colonoscopy to search for additional polyps as well as other gastrointestinal pathology.
\end{abstract}

Keywords: Colorectal polyp; Expulsion per rectum; Polypectomy

\section{Introduction}

The development of colorectal polyps, particularly adenomatous polyps, is associated with several risk factors, including age (i.e., increasing age is a risk factor), gender (i.e., more common in men), ethnicity (i.e., more common in African Americans), body mass index (BMI; i.e., increased BMI is associated with an increased risk), and lack of physical activity [1-15]. Many colorectal polyps are benign and include inflammatory polyps, hamartomatous polyps, and hyperplastic polyps. The other major type of polyp found, and of much greater significance due to its malignant potential, is the neoplastic adenoma. Adenomatous polyps have some degree of cytologic

Manuscript submitted June 2, 2018, accepted June 12, 2018

aDepartment of Internal Medicine, The Brooklyn Hospital Center, Academic Affiliate of The Icahn School of Medicine at Mount Sinai, Clinical Affiliate of The Mount Sinai Hospital, 121 Dekalb Avenue, Brooklyn, NY 11201, USA ${ }^{b}$ Department of Medicine, Henry J. Carter Specialty Hospital and Nursing Facility, 1752 Park Avenue, New York, NY 10035, USA

${ }^{\mathrm{c} C}$ Corresponding Author: Jamil Shah, 899 Woodmere Drive, Valley Stream, NY 11581, USA. Email: jshahid00@gmail.com

doi: https://doi.org/10.14740/gr1054w dysplasia and are recognized as precursors of colorectal cancer (CRC). They are estimated to be present in a quarter to a third of all adults [7]. Recently, several types of serrated polyps have been implicated in the development of CRC, as well $[16,17]$. Polypectomy during colonoscopy has been demonstrated to be significantly effective in reducing the incidence of CRC [18]. However, the spontaneous expulsion per rectum of a polyp is rare.

\section{Case Report}

A 60-year-old man, with past medical history of hypertension, diabetes mellitus, schizophrenia, and chronic constipation, visited his gastroenterologist with complaints of worsening lower abdominal pain and constipation for several weeks, not relieved with stool softeners and laxatives. He also reported, that during a bowel movement that morning, he had defecated "a piece of flesh" and bright red blood. The pain had been increasing in intensity, especially over the last 3 days. He was taking stool softeners, an over-the-counter colon cleanser, and magnesium citrate for his chronic constipation. Attributing the worsening abdominal pain to constipation, he consumed a higher dose of magnesium citrate. After a few hours, he had a large bowel movement with "a piece of flesh" and bright red blood per rectum. Subsequently, his abdominal pain improved, but he became concerned, collected the specimen in a container, and decided to visit his gastroenterologist. He had never experienced blood in the stool or black stools before. $\mathrm{He}$ denied any recent symptoms of fevers, chills, nausea, vomiting, diarrhea, change in appetite, or weight loss. He reported no family history of gastrointestinal malignancy. Previously, he had refused to undergo screening colonoscopy and to be screened with any of the other CRC screening modalities.

The patient was afebrile (temperature $36.8^{\circ} \mathrm{C}$ ) and hemodynamically stable (pulse rate 74 beats per minute, blood pressure 136/82 mm Hg). On physical exam, the abdomen was soft and not distended. There was mild tenderness at the left lower quadrant and normoactive bowel sounds. There was no rebound tenderness, guarding, rigidity, nor organomegaly. The specimen he collected appeared to be a polyp, and it was submitted to a laboratory for histopathologic evaluation. Macroscopic examination of the specimen brought by the patient in a container after spontaneous expulsion per rectum showed a tan polypoid lesion, roughly $1.4 \mathrm{~cm}$ in diameter (Fig. 1). Histologic examination of the spontaneously expulsed lesion revealed neoplastic glands lined by epithelium containing elongated 


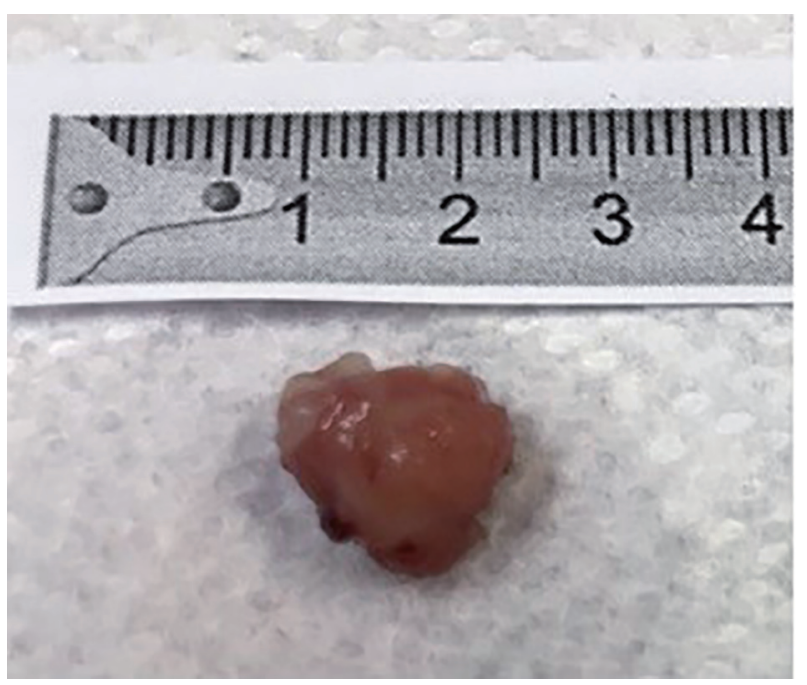

Figure 1. The specimen brought by the patient in a container after spontaneous expulsion per rectum. It appeared to be a colorectal pol$y p$, roughly $1.4 \mathrm{~cm}$ in diameter.

and hyperchromatic nuclei and demonstrated high nucleus to cytoplasm (N/C) ratio, features diagnostic of tubular adenoma.

The following day, the results of laboratory testing were reviewed, and the complete blood count $(\mathrm{CBC})$ showed white blood cell count of $19.0 \times 10^{9} / \mathrm{L}\left(4.0-11.0 \times 10^{9} / \mathrm{L}\right)$, hemoglobin of $12.8 \mathrm{~g} / \mathrm{dL}(13.5-17.5 \mathrm{~g} / \mathrm{dL})$ with an unknown baseline, hematocrit of $39 \%$ (38-54\%), and platelet count of $417 \times$ $10^{9} / \mathrm{L}\left(150-450 \times 10^{9} / \mathrm{L}\right)$. The comprehensive metabolic panel (CMP) showed blood urea nitrogen of $16 \mathrm{mg} / \mathrm{dL}(7-22 \mathrm{mg} /$ $\mathrm{dL})$ and creatinine of $0.8 \mathrm{mg} / \mathrm{dL}(0.6-1.3 \mathrm{mg} / \mathrm{dL})$, as well as normal liver function tests. The specimen was later reported as tubular adenoma (Fig. 2).

Colonoscopy was performed and revealed multiple polyps: a $1.8 \mathrm{~cm}$ pedunculated polyp in the descending colon (Fig. 3a), an 8 - $9 \mathrm{~mm}$ pedunculated polyp in the distal transverse colon (Fig. 3b), a $2 \mathrm{~cm}$ pedunculated polyp in the proximal transverse colon (Fig. 3c), and a $2 \mathrm{~cm}$ sessile polyp in the ascending colon (Fig. 3d). All of the polyps were removed with snare cautery polypectomy and submitted to a laboratory for histopathologic evaluation. They were later reported as tubular adenoma, except for the ascending colon polyp which was reported as tubulovillous adenoma.

At the patient's follow-up visit 2 weeks later, he reported feeling better. His chronic constipation has improved since then with a polyethylene glycol laxative.

\section{Discussion}

Colorectal polyps, growths protruding into the colorectal lumen above the surrounding mucosa, can be neoplastic or benign. Neoplastic adenomas are precancerous lesions that have the potential to become malignant. Such progression to adenocarcinoma is believed to occur over a period of roughly 10 years. Therefore, with appropriate screening and surveillance, these polyps can be removed to prevent the development of

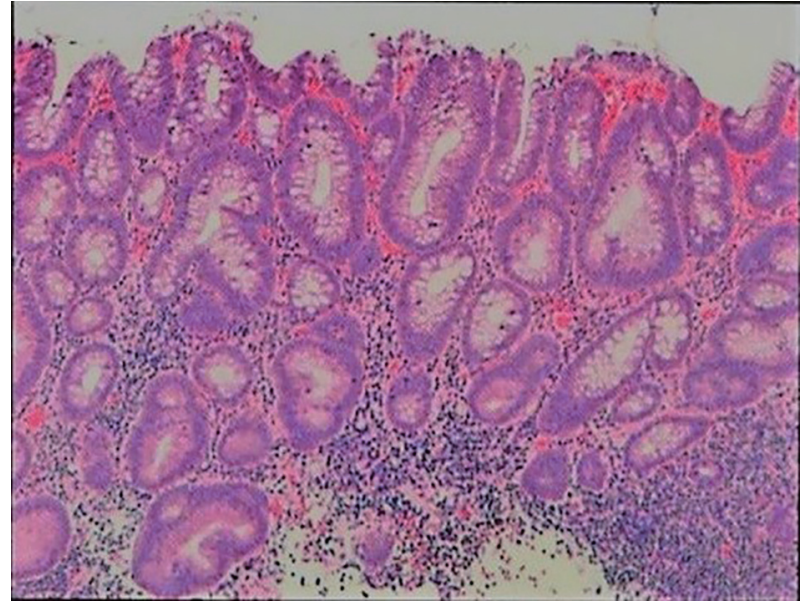

Figure 2. Histopathologic image of the colorectal polyp. The neoplastic glands are lined by hyperchromatic glandular epithelium. The elongated nuclei and reduced cytoplasmic mucin production are consistent with a large tubular adenoma. H\&E stain. Low-power magnification.

cancer $[19,20]$. Although there are various CRC screening modalities - fecal occult blood test (FOBT), fecal immunochemical test (FIT), double-contrast barium enema, computed tomography (CT) colonography, flexible sigmoidoscopy, and others - colonoscopy remains the gold standard test for detection of CRC [21]. Moreover, colonoscopy is performed for both diagnostic and therapeutic reasons, via polypectomy for visualized colorectal polyps.

The spontaneous expulsion per rectum of a polyp is rare, and the literature regarding such cases is limited. There have been several reported cases of rectal expulsion of lipomas [22$29]$. With an incidence of $0.035-4.4 \%$, lipomas are the secondmost common benign tumors of the colon [22]. In rare circumstances, the lipoma can self-detach and be expelled from the rectum. Such spontaneous expulsion primarily takes place among large, pedunculated lipomas that separate from their pedicles. In most cases, the cause of the event remains unknown [24]. The lipoma may necrose as it twists upon its pedicle or as that particular colonic segment intussuscepts [28].

To our knowledge, this is the first published case of spontaneous expulsion of an adenomatous polyp during defecation. The exact mechanism of self-detachment of the colorectal polyp is not well understood. Similar to lipomas, in large, pedunculated polyps, the pedicle can become twisted and strangled, leading to necrosis and self-amputation of the polyp. The base of this polyp indeed appeared necrotic on histology. Also, chronic constipation, as in our patient, can result in damage to the mucosal lining. Conceivably, a hard, dry stool could shear a large, pedunculated polyp from its base, causing it to be expulsed from the rectum. In our patient, given the adenomatous histopathology of the expulsed polyp, a complete examination with colonoscopy was warranted.

\section{Conclusions}

In conclusion, colorectal polyps are fairly common, and the 

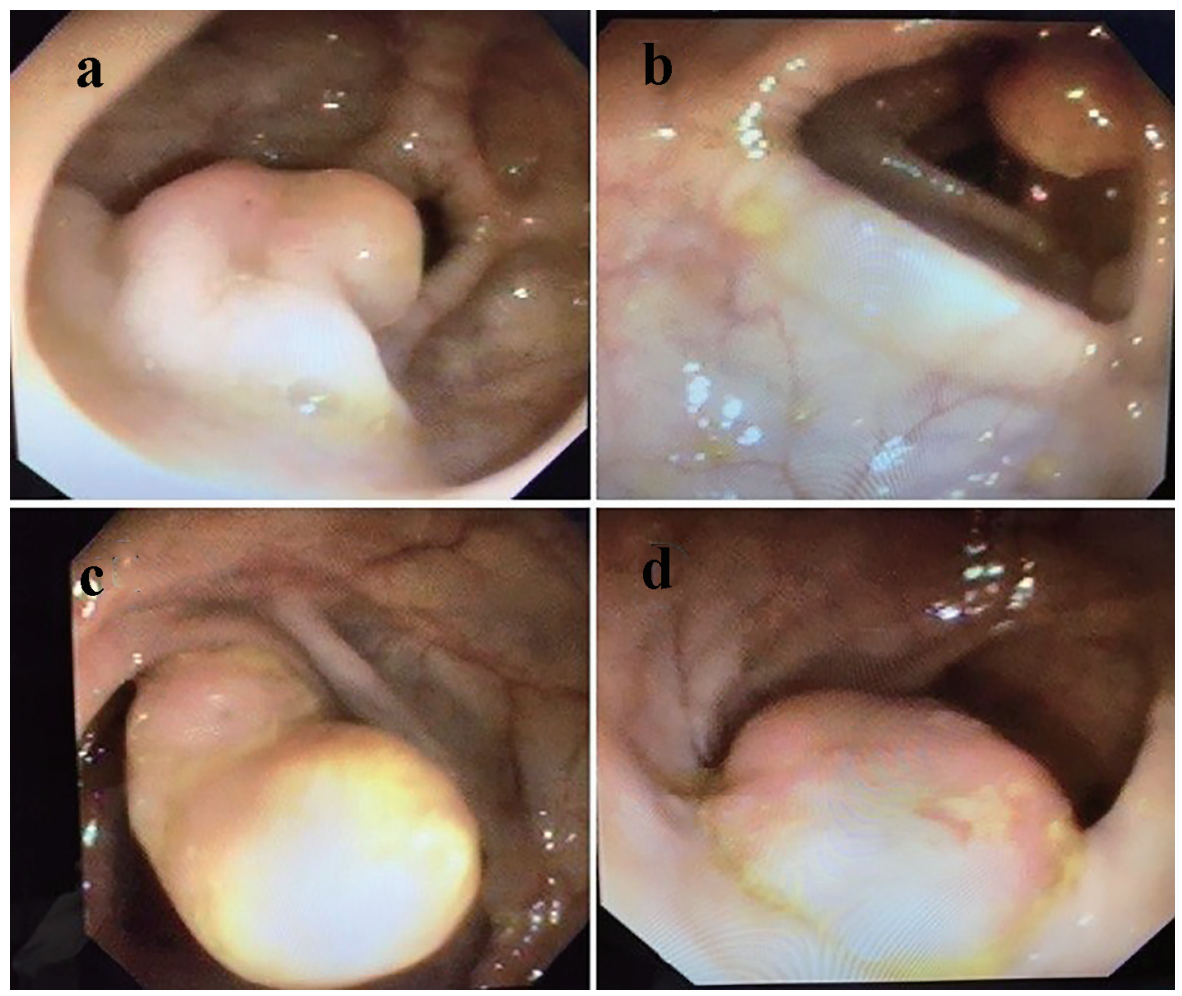

Figure 3. Endoscopic images of (a) a $1.8 \mathrm{~cm}$ pedunculated polyp in the descending colon, (b) an 8 - $9 \mathrm{~mm}$ pedunculated polyp in the distal transverse colon, (c) a $2 \mathrm{~cm}$ pedunculated polyp in the proximal transverse colon, and (d) a $2 \mathrm{~cm}$ sessile polyp in the ascending colon.

complete removal of adenomatous polyps during colonoscopy prevents the development of cancer. Meanwhile, the spontaneous expulsion per rectum of such polyps is exceedingly rare. Such a patient should undergo colonoscopy to search for additional polyps as well as other gastrointestinal pathology.

\section{Financial Disclosures}

The authors of this case report declare that no financial support nor grant support has been received for the preparation of this manuscript.

\section{Conflict of Interest}

The authors of this case report declare that they have no competing interests.

\section{References}

1. Carlsson G, Petrelli NJ, Nava H, Herrera L, Mittelman A. The value of colonoscopic surveillance after curative resection for colorectal cancer or synchronous adenomatous polyps. Arch Surg. 1987;122(11):1261-1263.

2. Heitman SJ, Ronksley PE, Hilsden RJ, Manns BJ, Rostom A, Hemmelgarn BR. Prevalence of adenomas and colorectal cancer in average risk individuals: a systematic review and meta-analysis. Clin Gastroenterol Hepatol. 2009;7(12):1272-1278.

3. Rex DK, Lehman GA, Hawes RH, Ulbright TM, Smith JJ. Screening colonoscopy in asymptomatic average-risk persons with negative fecal occult blood tests. Gastroenterology. 1991;100(1):64-67.

4. Rex DK, Lehman GA, Ulbright TM, Smith JJ, Pound DC, Hawes RH, Helper DJ, et al. Colonic neoplasia in asymptomatic persons with negative fecal occult blood tests: influence of age, gender, and family history. Am J Gastroenterol. 1993;88(6):825-831.

5. Rex DK. Colonoscopy: a review of its yield for cancers and adenomas by indication. Am J Gastroenterol. 1995;90(3):353-365.

6. Pendergrass CJ, Edelstein DL, Hylind LM, Phillips BT, Iacobuzio-Donahue C, Romans K, Griffin CA, et al. Occurrence of colorectal adenomas in younger adults: an epidemiologic necropsy study. Clin Gastroenterol Hepatol. 2008;6(9):1011-1015.

7. Williams AR, Balasooriya BA, Day DW. Polyps and cancer of the large bowel: a necropsy study in Liverpool. Gut. 1982;23(10):835-842.

8. Patel K, Hoffman NE. The anatomical distribution of colorectal polyps at colonoscopy. J Clin Gastroenterol. 2001;33(3):222-225.

9. Ben Q, An W, Jiang Y, Zhan X, Du Y, Cai QC, Gao J, et al. Body mass index increases risk for colorectal ad- 
enomas based on meta-analysis. Gastroenterology. 2012;142(4):762-772.

10. Nam SY, Kim BC, Han KS, Ryu KH, Park BJ, Kim HB, Nam BH. Abdominal visceral adipose tissue predicts risk of colorectal adenoma in both sexes. Clin Gastroenterol Hepatol. 2010;8(5):443-450 e441-442.

11. Wolin KY, Yan Y, Colditz GA. Physical activity and risk of colon adenoma: a meta-analysis. Br J Cancer. 2011;104(5):882-885.

12. Nguyen SP, Bent S, Chen YH, Terdiman JP. Gender as a risk factor for advanced neoplasia and colorectal cancer: a systematic review and meta-analysis. Clin Gastroenterol Hepatol. 2009;7(6):676-681 e671-673.

13. Lieberman DA, Holub JL, Moravec MD, Eisen GM, Peters D, Morris CD. Prevalence of colon polyps detected by colonoscopy screening in asymptomatic black and white patients. JAMA. 2008;300(12):1417-1422.

14. Ozick LA, Jacob L, Donelson SS, Agarwal SK, Freeman HP. Distribution of adenomatous polyps in AfricanAmericans. Am J Gastroenterol. 1995;90(5):758-760.

15. Karami S, Young HA, Henson DE. Earlier age at diagnosis: another dimension in cancer disparity? Cancer Detect Prev. 2007;31(1):29-34.

16. O'Connell BM, Crockett SD. The clinical impact of serrated colorectal polyps. Clin Epidemiol. 2017;9:113-125.

17. Rashtak S, Rego R, Sweetser SR, Sinicrope FA. Sessile serrated polyps and colon cancer prevention. Cancer Prev Res (Phila). 2017;10(5):270-278.

18. Baxter NN, Warren JL, Barrett MJ, Stukel TA, DoriaRose VP. Association between colonoscopy and colorectal cancer mortality in a US cohort according to site of cancer and colonoscopist specialty. J Clin Oncol. 2012;30(21):2664-2669.

19. Winawer SJ, Zauber AG, Ho MN, O'Brien MJ, Gottlieb LS, Sternberg SS, Waye JD, et al. Prevention of colorectal cancer by colonoscopic polypectomy. The National Polyp
Study Workgroup. N Engl J Med. 1993;329(27):19771981.

20. Atkin WS, Edwards R, Kralj-Hans I, Wooldrage K, Hart AR, Northover JM, Parkin DM, et al. Once-only flexible sigmoidoscopy screening in prevention of colorectal cancer: a multicentre randomised controlled trial. Lancet. 2010;375(9726):1624-1633.

21. Geiger TM, Ricciardi R. Screening options and recommendations for colorectal cancer. Clin Colon Rectal Surg. 2009;22(4):209-217.

22. Rocha M, Pereira S, Salgado M. Spontaneous expulsion per rectum of colonic lipoma. Clin Gastroenterol Hepatol. 2017;15(6):A19.

23. Kang B, Zhang Q, Shang D, Ni Q, Muhammad F, Hou L, Cui W. Resolution of intussusception after spontaneous expulsion of an ileal lipoma per rectum: a case report and literature review. World J Surg Oncol. 2014;12:143.

24. Kouritas VK, Baloyiannis I, Koukoulis G, Mamaloudis I, Zacharoulis D, Efthimiou M. Spontaneous expulsion from rectum: a rare presentation of intestinal lipomas. World J Emerg Surg. 2011;6:19.

25. Gupta AK, Mujoo V. Spontaneous autoamputation and expulsion of intestinal lipoma. J Assoc Physicians India. 2003;51:833.

26. Misra SP, Singh SK, Thorat VK, Gulati P, Malhotra V, Anand BS. Spontaneous expulsion per rectum of an ileal lipoma. Postgrad Med J. 1988;64(755):718-719.

27. Zamboni WA, Fleisher H, Zander JD, Folse JR. Spontaneous expulsion of lipoma per rectum occurring with colonic intussusception. Surgery. 1987;101(1):104-107.

28. Sidani SM, Tawil AN, Sidani MS. Extraction of a large self-amputated colonic lipoma: A case report. Int J Surg. 2008;6(5):409-411

29. Ghanem OM, Slater J, Singh P, Heitmiller RF, DiRocco JD. Pedunculated colonic lipoma prolapsing through the anus. World J Clin Cases. 2015;3(5):457-461. 